\title{
A Study on the Alteration Tendency of Physical Ability Index and Stress Feature Index of Elite Female Judoists in Intensity Training
}

\author{
Ming Chen \\ Physical Education College, Inner Mongolia Normal University \\ Hohhot 010020, China \\ E-mail: chen_mingtiyu@126.com
}

\begin{abstract}
A cluster analysis was conducted to preliminarily screen the physical ability index and stress feature index from the hormones measured in this study, and the alterations of the indexes in intensity training of elite female judoists were discussed. Results showed that the intensity training affected alterations of physical ability indexes, including LH, TT, T/C and PRL, and the stress feature indexes, including EN, ACTH, $\beta$-END and C. The results suggested that in intensity training, alterations of physical capacity were affected by several factors, such as endocrine indexes.
\end{abstract}

Keywords: Elite female judoists, Intensity training, Physical ability index, Stress feature index, Hormone

Intensity training will accelerate the production of catecholamine in the nerve centre and its downstream function, and accordingly regulate the material and oxygenic supply in the motorial muscle. As a stressor, tumbling is an important factor that influences the activities of autonomic nerve, because movement can increase the level of adrenalin and noradrenalin in the blood, and then influence the level of other hormones. Gonadotropin-gonadal axis is of great significance for the strength based movement. This paper discussed the variation of endocrine indexes of female judoists in intensity training and made a classification about the indexes, it will be a reference for the evaluation of body quality.

\section{Methods}

\subsection{Research object}

Ten judoists (age, $20.30 \pm 1.42$ year; stature, $167.50 \pm 4.92 \mathrm{~cm}$; weight, $65.10 \pm 7.96 \mathrm{Kg}$; training life, $4.60 \pm 1.26$ year; percentage body fat, $16.88 \pm 6.44 \%$; hemoglobin, $13.60 \pm 1.26 \mathrm{~g} / \mathrm{dL}$; systolic pressure, $119.50 \pm 10.12 \mathrm{mmHg}$; diastolic pressure, $77.00 \pm 6.32 \mathrm{mmHg}$ ) who were first class athletes or master sportsman were the research objects, they were not overtrained, had no cardiovascular disease and didn't eat any drugs that contain hormones.

\subsection{Training arrangement}

Training cycle was one week, specifically, 11 large intensity trainings would be done in one week, i.e. large intensity training on Thursday and Friday, less intensity training on Monday, Wednesday and Saturday and agilely arranged training on Tuesday according to athletes' situation. One class lasts 2 hours, and the intensity was controlled by observational method and the Rating of Perceived Exertion (RPE) recommended by Borg (Borg, 1962; Borg and Linderholm, 1970).

\subsection{Sampling}

Blood sample was taken every two weeks, totally four times, and blood sample was taken at three time points, i.e. before training, just after training and the next day morning. Venous blood was taken at 7:00-8:00 am; athletes were hollow and just after intensity training. Blood serum and blood plasma were separated according to the guideline of kit, and kept at low temperature. RPE and anxiety investigation were done at the same time with blood sampling.

\subsection{Tested indexes}

\subsubsection{Recorded athletes' rating of perceived exertion using the RPE table recommended by Borg}

1.4.2 Investigated athletes' anxiety according to the sport anxiety questionnaire revised by Zhu, Peili, et al.

1.4.3 The method of ${ }^{125}$ I radioimmunoassay gamma counting was used to detect adrenocorticotrophic hormone (ACTH), cortisol (C), total testosterone (T), follicle stimulating hormone (FSH), luteinizing hormone (LH), and prolactin (PRL), the kit was provided by DPC (Tianjin) Co., Ltd., $\beta$-endorphin ( $\beta$-END) was provided by Department of Neurobiology, The Second Military Medical University. For ECTH, the coefficient of variation within a single assay was $8.1 \%$, and the 
coefficient of variation between assays was $9.0 \%$, for $\mathrm{C}$, they were $5.0 \%$ and $10.0 \%$ respectively, for $\mathrm{T}$, they were $5.9 \%$ and $6.4 \%$ respectively, for FSH, they were $7.0 \%$ and $9.6 \%$ respectively, for, $\mathrm{LH}$, they were $6.0 \%$ and $9.8 \%$ respectively, for PRL, they were $6.0 \%$ and $10.0 \%$ respectively, and for $\beta$-END, they were $7.8 \%$ and $9.6 \%$ respectively. Epinephrine (E) and norepinephrine (NE) were detected by high performance liquid chromatography (HPLC).

\subsection{Index classification and evaluation}

After analyzing the data, the endocrine indexes were classified into physical ability indexes and stress feature indexes. The various indexes during the training were detected and evaluated according to the classification standard.

\subsection{Statistical analysis}

The data was analyzed by cluster analysis, Pearson correlation analysis and repeated measurement variance analysis, if there are unequal variances, data will firstly be revised then analyzed, $\mathrm{P}<0.05$.

\section{Results}

\subsection{Index classification}

The data about the indexes, including T, T/C, LH, FSH, PRL, ACTH, $\beta$-END, NE, E and C, were aggregated into one cluster after nine times of aggregation. The indexes were classified into two kinds, i.e. the indexes relating to physical ability (T, T/C, LH, FSH, PRL) and the indexes relating to stress feature (ACTH, $\beta$-END, NE, E and C). Pearson correlation analysis was conducted in the two kinds of indexes, it was indicated that indexes relating to anabolism were LH and $\mathrm{T}$, and there was a significant difference between $\mathrm{T}$ and $\mathrm{T} / \mathrm{C}(\mathrm{P}<0.01)$. The average of correlated index of each index compared with other indexes was used to calculate the typical index; it was shown that T, T/C and LH could be used as typical indexes to analyze the physical ability. Using the same calculating method, it was indicated that there was significant correlation between $\mathrm{E}$ and $\mathrm{NE}, \mathrm{ACTH}(\mathrm{P}<0.01, \mathrm{P}<0.05), \mathrm{C}$ and $\mathrm{NE}(\mathrm{P}<0.05), \beta$-END and ACTH, RPE $(\mathrm{P}<0.01, \mathrm{P}<0.05)$, RPE and $\mathrm{C}(\mathrm{P}<0.05)$, further analysis revealed that $\mathrm{E}, \mathrm{NE}, \beta-\mathrm{END}, \mathrm{C}, \mathrm{ACTH}$ and RPE could be used as the indexes to analyze the physical and psychological stress.

\subsection{The test of various indexes during the intensity training}

\subsubsection{The variation of indexes relating to physical ability}

As shown in table 1 that, in the first sampling, there was no significant difference between the LH level before training and just after training $(\mathrm{P}>0.05)$, but the LH level in the next day morning was higher than that before training $(\mathrm{P}<0.05)$ and just after training $(\mathrm{P}<0.05)$, no significant variation was shown in other sampling point. Total testosterone before training and in the next day morning in the second sampling was significantly lower than that in the first sampling $(\mathrm{P}<0.01)$, but no difference was found in total testosterone level just after training $(\mathrm{P}>0.05)$. As the going of training, the testosterone level in the next day morning in the fourth sampling was significantly lower than that in the first sampling $(\mathrm{P}<0.05)$. The variation of $\mathrm{T} / \mathrm{C}$ was similar to testosterone, $\mathrm{T} / \mathrm{C}$ in the second sampling was significantly lower than that in the first sampling $(\mathrm{P}<0.01)$, but $\mathrm{T} / \mathrm{C}$ just after training showed no significant difference $(\mathrm{P}>0.05)$. $\mathrm{T} / \mathrm{C}$ in the fourth sampling was significantly lower than that in the first sampling $(\mathrm{P}<0.05)$. In the fourth sampling, PRL just after training was significantly higher than that before training $(\mathrm{P}<0.01)$.

\subsubsection{The variation of indexes relating to stress feature}

In the beginning of intensity training, adrenalin just after training was significantly higher than that before training $(\mathrm{P}<0.05)$, with the further going of intensity training, in the fourth sampling, the adrenalin just after training was significantly lower than that before training $(\mathrm{P}<0.05)$. ACTH concentration in the third sampling was higher than that in other samplings $(\mathrm{P}<0.01)$, but ACTH in the next day morning was low $(\mathrm{P}<0.05)$. In the third sampling, $\beta$-END just after training was significantly higher than that in the first sampling and the second sampling $(\mathrm{P}<0.01, \mathrm{P}<0.05)$. In the fourth sampling, cortisol level before training was significantly lower than that in the third sampling $(\mathrm{P}<0.05)$, and cortisol level just after training and in the morning were higher than that before training $(\mathrm{P}<0.01, \mathrm{P}<0.01)$ (Table 2$)$.

\subsubsection{The variation of psychological indexes}

As shown in table 3 that athletes' score of rating of perceived exertion just after training and in the next day morning was significantly higher than that before training $(\mathrm{P}<0.01, \mathrm{P}<0.01)$.

\section{Discussion}

\subsection{Classification of indexes}

In intensity training, the variation of multiple body functions is represented by the interaction of various factors; it is mechanical to try to reflect the interaction process of various factors with one way or one direction in the job of body function evaluation. As the subject and object of training, athletes are greatly stimulated physically and psychologically, especially in the training of judo. Judo is a sport that has strong counterwork, and has high demand on athletes' physical ability and psychological reaction. In order to meet the physical and psychological need, human body will mobilize its 
potential; hence the activity of endocrine system is very important. During the sports, the dynamic equilibrium of the material and energy requires the hormones that are involved in assimilation and dissimilation. Usually, assimilation hormones are of significance for the physical ability of body and stress hormones is good for the body in intensity sport. The level of hormones during the intensity training of female judoists, were analyzed, it was indicated that the hormones could be classified into two kinds, in the first kind, LH, T and T/C of Gonadotropin-gonadal axis were dominant in response, in the second kind, ACTH, C, E, $\beta$-END and NE were sensitive to intensity training. Hence, the above two kinds of index system were named as indexes relating to physical ability and indexes relating to stress, the two index systems were used in the evaluation of athletes' body function in intensity training.

\subsection{The variation of indexes relating to physical ability}

The synthesis of testosterone is regulated by LH, normally, LH binds to the receptor on the Leydig cell membrane and activates adenyl cyclase, the concentration of cAMP will be increased, and accordingly the protein kinases that are dependent on cAMP will be activated, in that way, cholesterin will be transformed into $20 \alpha$-hydroxyl-cholesterin, and the synthesis of progesterone will be increased, finally testosterone will be synthesized. The secretion of testosterone has day and night rhythm, usually the highest level is at 8:00 in the morning and the lowest level is at twelve at night, but it is also influenced by wake time (Zhang, et al., 1996). The variation of LH, T and T/C can basically represent the characteristic of intensity training, i.e. with the going of training, the level of indexes relating to synthesis metabolism decreased. As the hormone that regulate the synthesis and secretion of testosterone, LH changed significantly in the beginning of this study, but later, testosterone changed significantly.

It was put forward by Hackney et al. (Hackney, et al., 1997; Hackney, et al., 1988) that the great changes of PRL would decrease the level of testosterone, PRL might increase the concentration of testosterone by enhancing the synthesis activity of Leydig cell or increasing the concentration of cholesterin and activating the enzymes needed by testosterone synthesis, or large or excessive amount of PRL could antagonize the function of LH and FSH (Wheeler et al., 1991; Wheeler et al., 1984). But there are other factors that might affect the variation of the testosterone.

As far as the T/C concerned, Vervoorn et al. reported that the T/C value of 6 rowing athletes who were elected to take part in the Olympic Games in 1988 in intensity training was 5-50\% lower than the T/C value when they stayed still (Vervoorn et al., 1991). In normal training, T/C value is a little different from the situation mentioned above, i.e. T/C value is not lower than $0.35 \times 10^{-3}$ as reported by the previous scholars, but when they are working, $\mathrm{T} / \mathrm{C}$ value is always about $30 \%$ lower than $\mathrm{T} / \mathrm{C}$ value when they stay still. The variation indicates that the trainees haven't get back to normal, even they are not in the state of overtraining. But the scholars still think that the decrease of $\mathrm{T} / \mathrm{C}$ value in several months will eventually lead to overtraining of the body. At $4.0 \mathrm{mmol}$, lactic acid has no relevant relationship with the variation of hormones. Lutoslawska observed the testosterone and cortisol level of five excellent canoeing athletes in $19 \mathrm{~km}$ and $42 \mathrm{~km}$ race (Lutoslawska, 1991), it was shown that the race would increase the cortisol level, and the increase was dependent on the time of race, i.e. the cortisol level in the $42 \mathrm{~km}$ race was higher than that in the $19 \mathrm{~km}$ race. Later, they found that the testosterone level significantly decreased in both games, and there was no significant difference between the testosterone levels induced by the two games, but the decrease of T/C value in $42 \mathrm{~km}$ race was larger than that in 19 $\mathrm{km}$ race. 18 hours after the game, testosterone, cortisol and $\mathrm{T} / \mathrm{C}$ value could get back to normal level. It can be seen that the $\mathrm{T} / \mathrm{C}$ value of female judoists showed a trend of getting back, whether it was induced by training needs further discussion.

\subsection{The alteration of indexes relating to stress}

In the practical training, stress reaction and emergency reaction are of equal importance. Stress reaction mainly means the basic endurance of body to the damage and stimulation, emergency reaction mainly means the watchful ability of body to emergency. The latter has close relationship with $\mathrm{E}$ and NE, which are mainly secreted by adrenal medulla. In vivo, after binding to their receptor, $\mathrm{E}$ and $\mathrm{NE}$ will activate phosphorylase, accelerate the glycogenolysis and improve the blood sugar, which will be propitious to the oxidation of lactic acid and the gluconeogenesis in the muscle. Besides, in intensity training, the environment, training task and the antagonists will stimulate the athletes' to response to the stress and emergency, the sympathetic-adrenergic-system will be strongly activated. Hence, the E level just after training showed a trend of increase, with the progress of training, E level just after training showed a trend of decrease, maybe athletes' response was lessened after they were familiar with the training plan and the environment.

$\beta$-END and ACTH come from a common precursor, i.e. POMC, when in stress, $\beta$-END and ACTH will be released to the blood together. The END can get to the brain and act on the neurons that are involved in the cardiovascular activity and reduce the activity of sympathetic nerve and enhance the activity of heart pneumogastric nerve. Stress can lead to the secretion of anterior pituitary hormone, such as ACTH, PRL and $\beta$-END. Study has shown that intensity training will lead to the increase of $\beta$-END level (Farrell, 1985; Elias, et al., 1986). Endogenous opioid peptide and its ramifications can repress $\mathrm{LH}$ and FSH, while opioid peptide's antagonist can promote the secretion of gonadotropin-gonadal axis hormones, the above situation is reasonable at least for women. In this study, it was indicated that $\beta$-END and ACTH after training showed a trend of increase, and after rest, they showed a trend of getting 
back, it was obvious that the activity of gonadotropin-gonadal axis was influenced.

Buono et al. showed in their study on the response of hypothalamic-pituitary-gonadal axis to short time training that short time training could lead to the increase of ACTH and $\mathrm{C}$, and the increase of $\mathrm{C}$ level was caused by the enhancement of adrenal cortex's activity (Buono, 1986). As an important stress hormone, C plays an important role in the material metabolism in intensity training, $\mathrm{C}$ can promote the proteolysis of extrahepatic tissue, especially the muscle, and accelerate the gluconeogenesis in the liver; in addition, $\mathrm{C}$ can promote the fat metabolism and the gluconeogenesis using fatty acid, which will be propitious to the continuous progress of movement; $\mathrm{C}$ is one of the most important hormones that increase the blood sugar, it can active the enzymes that are involved in gluconeogenesis in the liver, antagonize the activity of insulin, reduce muscle and fat tissue's sensitivity to insulin, and reduce the utilization of glucose in the peripheral tissue, so that increase the level of blood sugar for muscle movement. Hence, when there is high concentration recycled $\mathrm{C}$, blood sugar will be of high level, and the large consumption of blood sugar will influence the behavior of $\mathrm{C}$. Tabata et al. investigated the function of low intensity continuous movement on the hormones of serum, trainees were on fasting for 12 hours, and pedaled with the $50 \%$ intensity of maximal oxygen intake before training, there was no significant change in the indexes mentioned above, no matter it was exhausted training, training for 3 hours or systematic training (7W, average energy consumption every day is 531 kcal, i.e. $230 \mathrm{~J}$ ) (Tabata , et al., 1990); but in the later stage of training, the level of ACTH and C decreased with the reduction of blood sugar (Terada, et al., 2004). In this study, the variation of ACTH and C was inconsistent, and the reasons for that need further investigation.

If normal testees take hydrocortisone and insulin orally, serum cortisol will sharply increase, and the testosterone will decrease, while the LH and FSH don't change, it is indicated that endogenous and extrinsic increase of cortisol level will quantificationally lead to the decrease of recycling testosterone (Cumming, et al., 1983). Glucocorticoid can restrict the function of testicle through hypothalamic-pituitary-gonadal axis, 95\% recycling testosterone comes from Leydig cell, glucocorticoid can restrict the activity of LH receptor of Leydig cell and accordingly restrict the secretion of testosterone (Wheeler, et al., 1994).

RPE is a simple and effective medical supervision method to evaluate the intensity of training; it is an index between physiology and psychology. In 1962, Borg firstly put forward the table of 21 point to determine the rating of perceived exertion, and in 1970, he put forward the table of 15 point to evaluate the variation of body function relating to intensity of training. The table was used to detect the RPE of healthy adults and trainees, accordingly got the relevant degree of physiological indexes and psychological indexes. After that, the table was widely used in swimming, running and patients (Borg and Linderholm, 1970). As a matter of fact, the psychological exhibition of RPE reflects the variation of physiological function, that is why the RPE indexes and physiological indexes are detected and analyzed at the same time; human has strong ability to sense the consumption of physical power, i.e. perceiving exertion. The sense of physical power will provide people with the information about the body's endurance degree and suffering degree for the intensity of training. In the beginning of sport, if the intensity of training is appropriate, even it is a little hard, sport will become a pleasant feeling. So psychologist, physiologist and doctor show great zest in studying the relationship between physical ability perceiving and intensity, and in studying the relationship between physical ability perceiving and the symptom of disease as well as body function of athletes. Basing on the situation mentioned above, many scholars think that the subjective feeling should be taken as a meaningful index, and be quantified, so that the method will be used by most people without regard to sex, age and race. Borg firstly put forward "rating of perceived exertion" according to the concept mentioned above.

\subsection{Further discussion}

As far as the evaluation of body function of athletes concerned, the variation of index should be consistent with the exterior representation of body function. However, judo is special compared with the other periodical sports item, it is difficult to evaluate the body function of judoists by achievement. Hence, we introduce some indexes, such as rating of perceived exertion, into the evaluation of body function, and we think that comprehensive evaluation is better than single index evaluation.

\section{References}

Borg G. (1962). Physical Performance and perceived exertion. [J]. Lund: Gleerup. 1-63.

Borg G and Linderholm H. (1970). Exercise performance and perceived exertion in patients with coronary insufficiency, arterial hypertension and vasoregulatory asthenia. [J]. Acta Med Scand. 187(1-2):17-26.

Buono MJ. Yeager JE and Hodgdon JA. (1986). Plasma adrenocorticotropin and cortisol responses to brief high-intensity exercise in humans [J]. J Appl Physiol. 61(4):1337-9.

Cumming DC. Quigley ME and Yen SS. (1983). Acute suppression of circulating testosterone levels by cortisol in men [J]. J Clin Endocrinol Metab, 57 (3):671-3. 
Elias AN. Iyer K. Pandian MR, et al. (1986). Beta-endorphin/beta-lipotropin release and gonadotropin secretion after acute exercise in normal males. [J]. J Appl Physiol. 61(6):2045-9.

Farrell PA. (1985). Exercise and endorphins--male responses [J]. Med Sci Sports Exerc. 17(1): 89-93.

Hackney AC. Fahrner CL and Stupnicki R. (1997). Reproductive hormonal responses to maximal exercise in endurance-trained men with low resting testosterone levels. [J]. Exp Clin Endocrinol Diabetes, 105 (5): 291-5.

Hackney AC. Sinning WE and Bruot BC. (1988). Reproductive hormonal profiles of endurance-trained and untrained males. [J]. Med Sci Sports Exerc. 20 (1): 60-5.

Lutoslawska G. Obminski Z. Krogulski A. et al. (1991). Plasma cortisol and testosterone following 19-km and 42-km kayak races [J]. J Sports Med Phys Fitness. 31(4): 538-42.

Tabata I. Atomi Y. Kanehisa H, et al. (1990). Effect of high-intensity endurance training on isokinetic muscle power[J]. Eur J Appl Physiol Occup Physiol. 60(4): 254-8.

Terada S. Tabata I and Higuchi M. (2004). Effect of high-intensity intermittent swimming training on fatty acid oxidation enzyme activity in rat skeletal muscle [J]. Jpn J Physiol. 54(1): 47-52.

Vervoorn C. Quist AM. Vermulst LJ. et al. (1991). The behaviour of the plasma free testosterone/cortisol ratio during a season of elite rowing training. [J]. Int J Sports Med, 12 (3): 257-63.

Wheeler G. Cumming D. Burnham R, et al. (1994). Testosterone, cortisol and catecholamine responses to exercise stress and autonomic dysreflexia in elite quadriplegic athletes. [J]. Paraplegia. 32(5): 292-9.

Wheeler GD. Singh M. Pierce WD. et al. (1991). Endurance training decreases serum testosterone levels in men without change in luteinizing hormone pulsatile release [J]. J Clin Endocrinol Metab. 72 (2): 422-5.

Wheeler GD. Wall SR. Belcastro AN. et al. (1984). Reduced serum testosterone and prolactin levels in male distance runners. [J]. JAMA. 252(4): 514-6.

Zhang, Jingru and Qiao, Jiantian. (1996). Physiology. The fourth edition. [M]. Beijing. People's Medical Publishing House. 370-413. 
Table 1. Variation of indexes relating to physical ability

\begin{tabular}{|c|c|c|c|c|c|}
\hline & $\mathrm{FSH}$ & $\mathrm{LH}$ & $\mathrm{T}$ & $\mathrm{T} / \mathrm{C}$ & PRL \\
\hline \multicolumn{6}{|l|}{ The first test } \\
\hline $\begin{array}{l}\text { Before } \\
\text { training }\end{array}$ & $40.89 \pm 8.93$ & $4.96 \pm 0.76$ & $0.32 \pm 0.08$ & $0.0025 \pm 0.0006$ & $11.54 \pm 4.02$ \\
\hline $\begin{array}{l}\text { Just after } \\
\text { training }\end{array}$ & $29.18 \pm 8.37$ & $5.16 \pm 0.54$ & $0.29 \pm 0.10$ & $0.0021 \pm 0.0007$ & $14.46 \pm 4.10$ \\
\hline $\begin{array}{c}\text { The next day } \\
\text { morning }\end{array}$ & $29.96 \pm 7.05$ & $5.95 \pm 0.86 \mathrm{ab}$ & $0.37 \pm 0.13$ & $0.0028 \pm 0.0010$ & $13.52 \pm 4.20$ \\
\hline \multicolumn{6}{|l|}{$\begin{array}{c}\text { The second } \\
\text { test }\end{array}$} \\
\hline $\begin{array}{l}\text { Before } \\
\text { training }\end{array}$ & $25.19 \pm 6.05$ & $4.09 \pm 0.86$ & $0.17 \pm 0.07 \mathrm{cc}$ & $0.0013 \pm 0.0005 \mathrm{c}$ & $9.65 \pm 4.54$ \\
\hline $\begin{array}{l}\text { Just after } \\
\text { training }\end{array}$ & $37.02 \pm 10.23$ & $3.79 \pm 0.76$ & $0.18 \pm 0.09$ & $0.0015 \pm 0.0009$ & $10.63 \pm 2.94$ \\
\hline $\begin{array}{c}\text { The next day } \\
\text { morning }\end{array}$ & $28.20 \pm 9.24$ & $3.98 \pm 0.77$ & $0.20 \pm 0.10 \mathrm{dd}$ & $0.0015 \pm 0.0008$ & $13.36 \pm 4.85$ \\
\hline \multicolumn{6}{|l|}{ The third test } \\
\hline $\begin{array}{l}\text { Before } \\
\text { training }\end{array}$ & $29.52 \pm 10.20$ & $4.73 \pm 0.79$ & $0.24 \pm 0.09$ & $0.0019 \pm 0.0008$ & $12.59 \pm 4.72$ \\
\hline $\begin{array}{l}\text { Just after } \\
\text { training }\end{array}$ & $29.16 \pm 5.93$ & $5.06 \pm 0.76$ & $0.18 \pm 0.07$ & $0.0014 \pm 0.0005$ & $12.89 \pm 4.65$ \\
\hline $\begin{array}{c}\text { The next day } \\
\text { morning }\end{array}$ & $30.79 \pm 6.70$ & $4.30 \pm 0.87$ & $0.28 \pm 0.11$ & $0.0022 \pm 0.0009$ & $12.09 \pm 4.20$ \\
\hline \multicolumn{6}{|l|}{ The fourth test } \\
\hline $\begin{array}{l}\text { Before } \\
\text { training }\end{array}$ & $37.87 \pm 10.18$ & $4.16 \pm 0.77$ & $0.23 \pm 0.06$ & $0.0020 \pm 0.0007$ & $8.62 \pm 3.03$ \\
\hline $\begin{array}{l}\text { Just after } \\
\text { training }\end{array}$ & $31.12 \pm 10.83$ & $4.58 \pm 0.93$ & $0.19 \pm 0.10$ & $0.0013 \pm 0.0008$ & $15.08 \pm 3.26 \mathrm{aa}$ \\
\hline $\begin{array}{c}\text { The next day } \\
\text { morning }\end{array}$ & $33.22 \pm 7.37$ & $4.54 \pm 0.59$ & $0.23 \pm 0.09 \mathrm{~d}$ & $0.0017 \pm 0.0007 \mathrm{~d}$ & $12.41 \pm 4.37$ \\
\hline
\end{tabular}
a: $\mathrm{P}<0.05$ aa: $\mathrm{P}<0.01$ compared with the situation before training
b: $\mathrm{P}<0.05$ bb: $\mathrm{P}<0.01$ compared with the situation just after training
c: $\mathrm{P}<0.05$ cc: $\mathrm{P}<0.01$ compared with the situation before training in the first sampling.
$\mathrm{d}: \mathrm{P}<0.05 \mathrm{dd}: \mathrm{P}<0.01$ compared with the situation of the next day morning in the first sampling. 
Table 2. Variation of indexes relating to stress feature

\begin{tabular}{|c|c|c|c|c|c|}
\hline & $\mathrm{E}$ & $\mathrm{NE}$ & $\mathrm{ACTH}$ & $\beta$-END & $\mathrm{C}$ \\
\hline \multicolumn{6}{|l|}{ The first test } \\
\hline $\begin{array}{l}\text { Before } \\
\text { training }\end{array}$ & $59.44 \pm 22.26$ & $271.55 \pm 126.62$ & $16.67 \pm 4.07$ & $6.01 \pm 3.31$ & $127.94 \pm 12.41$ \\
\hline $\begin{array}{l}\text { Just after } \\
\text { training }\end{array}$ & $107.89 \pm 28.23 \mathrm{aa}$ & $474.26 \pm 179.74$ & $17.94 \pm 4.82$ & $8.02 \pm 4.32$ & $141.24 \pm 7.92$ \\
\hline $\begin{array}{l}\text { Next day } \\
\text { morning }\end{array}$ & $64.79 \pm 15.28 b$ & $259.70 \pm 127.09$ & $18.14 \pm 4.32$ & $4.71 \pm 3.23$ & $134.01 \pm 13.14$ \\
\hline \multicolumn{6}{|l|}{$\begin{array}{c}\text { The second } \\
\text { test }\end{array}$} \\
\hline $\begin{array}{l}\text { Before } \\
\text { training }\end{array}$ & $71.15 \pm 21.31$ & $246.95 \pm 146.89$ & $17.89 \pm 4.63$ & $8.71 \pm 4.43$ & $128.47 \pm 12.01$ \\
\hline $\begin{array}{c}\text { Just after } \\
\text { training }\end{array}$ & $98.43 \pm 23.02$ & $375.42 \pm 148.22$ & $20.17 \pm 5.57$ & $10.17 \pm 3.83$ & $126.83 \pm 13.70$ \\
\hline $\begin{array}{l}\text { Next day } \\
\text { morning }\end{array}$ & $63.47 \pm 27.19$ & $271.45 \pm 167.74$ & $19.79 \pm 5.80$ & $8.76 \pm 3.09$ & $133.69 \pm 11.78$ \\
\hline \multicolumn{6}{|c|}{ The third test } \\
\hline $\begin{array}{l}\text { Before } \\
\text { training }\end{array}$ & $72.51 \pm 18.86$ & $311.70 \pm 136.74$ & $17.61 \pm 3.99$ & $7.81 \pm 4.52$ & $127.59 \pm 13.21$ \\
\hline $\begin{array}{l}\text { Just after } \\
\text { training }\end{array}$ & $85.72 \pm 21.12$ & $332.46 \pm 161.28$ & $26.27 \pm 4.60 \mathrm{acd}$ & $15.07 \pm 3.62 \mathrm{ccd}$ & $132.98 \pm 9.12$ \\
\hline $\begin{array}{l}\text { Next day } \\
\text { morning }\end{array}$ & $64.77 \pm 19.10$ & $333.15 \pm 137.67$ & $21.57 \pm 4.22 \mathrm{~b}$ & $9.24 \pm 3.71$ & $131.00 \pm 8.44$ \\
\hline \multicolumn{6}{|c|}{ The fourth test } \\
\hline $\begin{array}{l}\text { Before } \\
\text { training }\end{array}$ & $61.18 \pm 23.24$ & $297.30 \pm 124.43$ & $18.36 \pm 3.36$ & $9.93 \pm 4.56$ & $114.66 \pm 12.32$ \\
\hline $\begin{array}{c}\text { Just after } \\
\text { training }\end{array}$ & $80.30 \pm 20.54 c$ & $387.92 \pm 185.59$ & $19.58 \pm 4.87 \mathrm{e}$ & $12.28 \pm 3.95$ & $140.58 \pm 10.62 \mathrm{ae}$ \\
\hline $\begin{array}{l}\text { Next day } \\
\text { morning }\end{array}$ & $69.65 \pm 20.75$ & $196.25 \pm 122.64$ & $18.78 \pm 3.12$ & $9.06 \pm 4.33$ & $134.99 \pm 8.66 \mathrm{ab}$ \\
\hline
\end{tabular}

a: $\mathrm{P}<0.05$ aa: $\mathrm{P}<0.01$ compared with the situation before training

b: $\mathrm{P}<0.05$ bb: $\mathrm{P}<0.01$ compared with the situation just after training

c: $\mathrm{P}<0.05$ cc: $\mathrm{P}<0.01$ compared with the situation just after training in the first sampling

$\mathrm{d}: \mathrm{P}<0.05 \mathrm{dd}: \mathrm{P}<0.01$ compared with the situation just after training in the second sampling

e: $\mathrm{P}<0.05$ ee: $\mathrm{P}<0.01$ compared with the situation just after training in the third sampling 
Table 3. Variation of psychological indexes

\begin{tabular}{ccc}
\hline & RPE & ANX \\
\hline The first test & $6.00 \pm 0.00$ & $16.30 \pm 1.70$ \\
Before training & $12.00 \pm 1.41$ & $16.90 \pm 3.45$ \\
Just after training & $10.50 \pm 1.84 \mathrm{~b}$ & $16.20 \pm 1.75$ \\
Next day morning & & \\
The second test & $11.25 \pm 1.23$ & $14.90 \pm 1.79$ \\
Before training & $12.50 \pm 1.83$ & $14.60 \pm 1.43$ \\
Just after training & $11.00 \pm 0.94$ & $15.30 \pm 2.06$ \\
Next day morning & & \\
The third test & $10.00 \pm 1.05$ & $16.20 \pm 2.20$ \\
Before training & $12.00 \pm 3.25$ & $15.90 \pm 1.66$ \\
Just after training & $9.65 \pm 2.06$ & $16.30 \pm 1.89$ \\
Next day morning & & \\
The fourth test & $11.05 \pm 2.41$ & $15.80 \pm 2.49$ \\
Before training & $11.90 \pm 2.32$ & $16.30 \pm 2.67$ \\
Just after training & $11.20 \pm 1.48$ & $16.30 \pm 2.58$ \\
Next day morning & & \\
\hline
\end{tabular}

a: $\mathrm{P}<0.05$ aa: $\mathrm{P}<0.01$ compared with the situation before training

b: $\mathrm{P}<0.05$ bb: $\mathrm{P}<0.01$ compared with the situation just after training 